
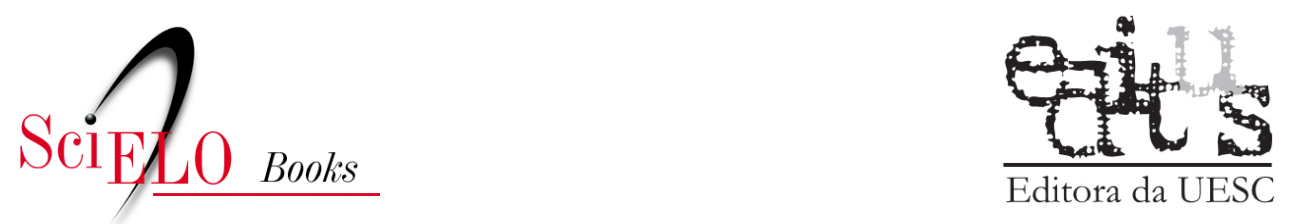

\title{
4 - A oralidade no ensino fundamental o gênero seminário como objeto de ensino
}

\author{
Cíntia Rodrigues Araújo Coelho \\ Valdinar Custódio Filho \\ Wilson Júnior de Araújo Carvalho
}

\section{SciELO Books / SciELO Livros / SciELO Libros}

COELHO, C. R. A., CUSTÓDIO FILHO, V., and CARVALHO, W. J. A. $A$ oralidade no ensino fundamental: o gênero seminário como objeto de ensino. In: AZEVEDO, I. C. M., ed. Práticas dialógicas de linguagem: possibilidades para o ensino de língua portuguesa [online]. Ilhéus, BA: EDITUS, 2018, pp. 83-107. ISBN: 978-85-7455-494-5. https://doi.org/10.7476/97885745554945.0004.

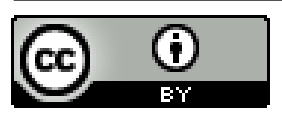

All the contents of this work, except where otherwise noted, is licensed under a Creative Commons Attribution 4.0 International license.

Todo o conteúdo deste trabalho, exceto quando houver ressalva, é publicado sob a licença Creative Commons Atribição 4.0.

Todo el contenido de esta obra, excepto donde se indique lo contrario, está bajo licencia de la licencia Creative Commons Reconocimento 4.0. 


\title{
4 \\ A ORALIDADE NO \\ ENSINO FUNDAMENTAL: \\ O GÊNERO SEMINÁRIO COMO \\ OBJETO DE ENSINO
}

\author{
Cíntia Rodrigues Araújo Coelho ${ }^{1}$ \\ Valdinar Custódio Filho \\ Wilson Júnior de Araújo Carvalho 3 \\ Universidade Estadual do Ceará
}

\section{Introdução}

Este estudo tem como objetivo discutir o trabalho com a oralidade na escola e as implicaçôes para o desenvolvimento da competência discursiva dos alunos a partir da prática de ensino dos gêneros orais. $\mathrm{O}$ interesse pelo tema surgiu ao observarmos que os gêneros orais presentes nos manuais de ensino são tratados de forma superficial, trazendo pouca contribuição para o aprimoramento das práticas orais na escola. Concentramos nossas reflexôes no estudo do gêneros seminário como prática social discursiva

1 Aluna do Mestrado Profissional em Letras (PROFLETRAS) da Universidade Estadual do Ceará (UECE). Bolsista da Capes. E-mail: <profcintia8@gmail.com>.

2 Professor do Mestrado Profissional em Letras (PROFLETRAS) da Universidade Estadual do Ceará (UECE); professor do Departamento de Letras Vernáculas da Universidade Federal do Ceará (UFC). E-mail: <valdinarcustodio@gmail.com>.

3 Professor do Mestrado Profissional em Letras (PROFLETRAS) da Universidade Estadual do Ceará (UECE). E-mail: <wiljrac@gmail.com>. 
inserida nos manuais didáticos de ensino fundamental. Optamos por esse gênero como objeto de estudo por compreendermos que a exposição oral é um evento comunicativo presente nas mais variadas esferas sociais; portanto, é papel da escola capacitar os alunos para produzi-lo, refletindo sobre suas especificidades a partir da mediação do professor.

Nosso estudo está dividido em três seçôes. Iniciamos explicitando alguns conceitos sobre o trabalho com a oralidade na escola, além de refletir sobre as especificidades do gêneros seminário sob a perspectiva dos teóricos da Escola de Genebra (SCHNEUWLY et al., 2010). Na sequência, analisamos três propostas de produção de um seminário em duas séries distintas do ensino fundamental, reformulando uma das propostas à luz do sociointeracionismo. Concluímos refletindo sobre a relevância do trabalho sistemático com a oralidade nas aulas de língua portuguesa a partir da visão do gênero seminário como técnica de ensino socializado e objeto de ensino-aprendizagem.

\section{Reflexóes acerca dos gêneros: uma perspectiva sociointeracionista}

Há um consenso entre os documentos oficiais de ensino e as teorias linguísticas voltadas para o ensino de que o desenvolvimento da oralidade é parte importante da formação global do educando. Concordamos com essa ideia, pois compreendemos que a oralidade deve ser aprimorada na escola, considerando que o aluno passará por diferentes situaçôes sociais nas quais serão exigidos domínio e adequação dos gêneros orais às situações comunicativas. Os Parâmetros Curriculares Nacionais preconizam a importância do trabalho com a oralidade concebendo-a como instrumento para o exercício da cidadania dentro e fora da escola:

Nas inúmeras situaçôes sociais do exercício da cidadania que se colocam fora dos muros da escola 
- a busca de serviços, as tarefas profissionais, os encontros institucionalizados, a defesa de seus direitos e opiniôes - os alunos serão avaliados (em outros termos, aceitos ou discriminados) à medida que forem capazes de responder a diferentes exigências de fala e de adequação às características próprias de diferentes gêneros do oral. Dessa forma, cabe à escola ensinar o aluno a utilizar a linguagem oral no planejamento e realização de apresentaçōes públicas (BRASIL, 1997, p. 25).

Entretanto, podemos observar que há uma grande distância entre a teoria e a prática, como afirmam Dolz, Schneuwly e Haller (2010, p. 125):

\begin{abstract}
Embora a linguagem oral esteja bastante presente nas salas de aula (nas rotinas cotidianas, na leitura de instruçóes, na correção de exercícios etc.), afirma-se frequentemente que ela não é ensinada, a não ser incidentalmente durante atividades diversas e pouco controladas. $\mathrm{O}$ ensino escolar da língua oral e de seu uso ocupa atualmente um lugar limitado.
\end{abstract}

Durante nossa experiência como docentes na educação básica, temos observado que, apesar de reconhecerem a importância do desenvolvimento da oralidade, muitos professores desconhecem as especificidades dos gêneros orais e frequentemente associam a dificuldade dos alunos em produzir textos eficientes à incapacidade ou desinteresse dos educandos. Essa perspectiva demonstra que a oralidade é o eixo da linguagem menos prestigiado no currículo escolar desse segmento educacional, contrariando as orientaçóes dos documentos oficiais de ensino.

Em sua maioria, os manuais didáticos corroboram o descaso com a oralidade tratando os gêneros orais de forma superficial, sem sistematizar os elementos constitutivos dessa modalidade de comunicação. $\mathrm{O}$ trabalho com a oralidade na escola é de fato muito limitado, como constata Goulart (2005, p. 19): 
Esse espaço era limitado a atividades como leituras em voz alta e discussóes informais sobre temas relacionados aos conteúdos das diversas disciplinas. Não havia o objetivo de propiciar o desenvolvimento da competência linguístico-comunicativa dos alunos, pois o essencial era verificar o domínio do conteúdo escolar apresentado.

Muitos são os gêneros orais passíveis de realização na escola, tanto na esfera literária quanto na não literária. Entretanto, o gênero seminário parece ser didático por excelência, pois é um instrumento de socialização do conhecimento. Adotamos a definição de exposição oral proposta por Dolz et al. (2010, p. 185), que a concebem como "um gênero textual público, relativamente formal e específico, no qual um expositor especialista dirige-se a um auditório, de maneira (explicitamente) estruturada, para lhe transmitir informaçóes, descrever-lhe ou the explicar alguma coisa”. O gênero seminário deve, portanto, ser reconhecido como instrumento destinado ao ensino-aprendizagem de conteúdos específicos, necessitando ser abordado de forma sistemática e como objeto de estudo a ser apreendido pelos educandos.

Bernardes e Gonçalves (2010) também defendem a utilização do seminário como técnica de ensino socializado na qual a prática pedagógica não fica restrita à facilitação da aprendizagem, mas promove também um ensino crítico e criativo. Além disso, concebemos o seminário como um gênero multididático, pois permite ao aluno-expositor desenvolver uma série de atividades de linguagem, como leitura para pesquisa, elaboração de textos escritos (necessários à organização da apresentação oral) e organização de sequências argumentativas e expositivas. A prática do seminário pode, também, promover o diálogo entre as diferentes áreas do conhecimento, considerando-se que se trata de um gênero passível de ocorrer nas aulas de qualquer disciplina. Logo, torna-se clara a importância de uma abordagem sistemática do gênero seminário, concebendose tal gênero como objeto de estudo com características próprias a 
serem apreendidas por seus usuários e como instrumento de um discurso planejado e com objetivos específicos a serem alcançados. Nessa perspectiva, Dolz et al. (2010) apontam três dimensóes ensináveis da exposição oral, que consideramos essenciais no trabalho com o gênero seminário na escola:

a) a situação de comunicação: o aluno deve estar consciente de seu papel de expositor-especialista que se dirige a um público específico (no caso, outros alunos) para transmitir um conteúdo. Nessa situação de comunicação, o aluno-expositor deverá dominar não só o conteúdo a ser explicitado, mas também as estratégias discursivas que garantirão o aprendizado do seu auditório;

b) a organização interna da exposição: a fase de preparação da exposição oral capacita o aluno para planejar um texto relativamente longo, visto que será necessária a organização das informaçóes disponíveis para garantir a coerência da exposição. Essa é uma fase imprescindível para garantir a progressão temática e evitar que o seminário se transforme em uma sequência de informaçóes desconexas;

c) as características linguísticas: a didática envolvendo um gênero expositivo deve fornecer ao aluno subsídios para que este possa compreender as sinalizaçóes textuais específicas desse tipo de discurso. $\mathrm{O}$ aluno deve ser capaz de elencar as diferentes ações linguísticas disponíveis de acordo com a necessidade no momento da enunciação - articular enunciados, marcar temporalmente sua fala, reformular, exemplificar e sintetizar seu texto.

Essas dimensóes podem ser trabalhadas nas diferentes etapas de planejamento e execução de um seminário, levando o educando a refletir sobre as etapas da elaboração de um gênero secundárió ${ }^{4}$. Na proposta de atividade reelaborada, explicitamos como é possível

4 Segundo Bakhtin (1992), os gêneros secundários são aqueles que aparecem em circunstâncias de comunicação cultural mais complexas, principalmente (mas não exclusivamente) escritas. Não estão mais ligados de maneira imediata a uma situação de comunicação informal, e sua forma revela, frequentemente, uma construção mais elaborada. 
abordar esse gênero de forma sistemática, conferindo-lhe o verdadeiro caráter de instrumento e objeto de ensino que pode contribuir para uma prática pedagógica interativa e produtiva.

\section{Didatização do gênero seminário: análise e reformulação}

Como planejar atividades que privilegiem o trabalho com gêneros orais de forma verdadeiramente pedagógica? Os livros didáticos têm abordado essa competência de maneira adequada? As concepçóes de oralidade que subjazem aos manuais são suficientes para garantir um ensino adequado? Ao buscar respostas para esses questionamentos, procedemos à análise de três propostas de produção do gênero seminário no ensino fundamental.

As propostas foram retiradas de três manuais pertencentes a duas coleçôes distintas do conjunto PNLD 2014 e utilizadas em escolas públicas do município de Fortaleza. As atividades aqui expostas destinam-se aos $7^{\circ}$ e $8^{\circ}$ anos do ensino fundamental, mas, para determinar a escolha destas, analisamos as propostas de produção do gêneros seminário em todos os livros das duas coleçôes. Observamos como o gênero seminário era conceituado, se os temas propostos estavam compatíveis com o caráter pedagógico do gênero e avaliamos se a atividade contemplava as dimensóes ensináveis propostas por Dolz et al. (2010), considerando que uma das coleçóes trazia em sua referência bibliográfica o trabalho desses autores referente aos gêneros orais.

Explicitamos, nas próximas subseções, as análises das atividades selecionadas.

5 Programa Nacional do Livro Didático. 


\section{Atividade 1}

Essa atividade faz parte da coleção Vontade de saber Português, elaborada por Rosemeire Alves e Tatiane Brugnerotto, editada pela FTD e destinada ao $7^{\circ}$ ano do ensino fundamental. A atividade é parte integrante do capítulo 2, que traz como temática a exploração do trabalho infantil.

\section{QUADRO 1 - Atividade de produção oral}

\section{Produção oral}

Seminário

A exploração do trabalho infantil é um assunto complexo, que permite muitas abordagens e discussões. Por isso, esse é um tema que pode ser mais bem estudado por meio de um seminário (uma apresentação em grupo, na qual são expostas, oralmente, informações obtidas por meio de pesquisas).

1. Observe o gráfico a seguir e conheça outras informações sobre o trabalho infantil.

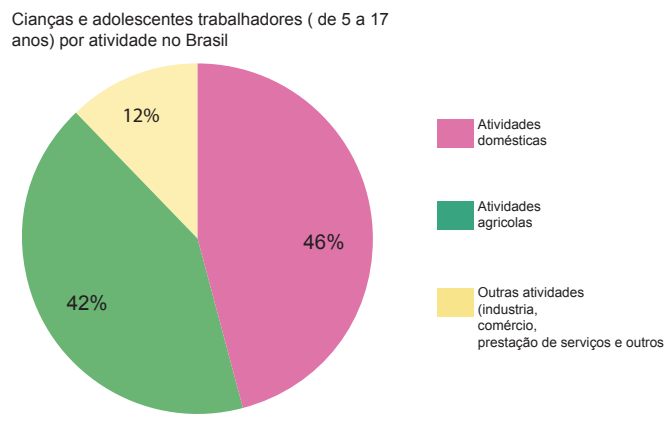

a) O gráfico acima é chamado de gráfico de setor. Esse gráfico é usado para representar dados obtidos por meio de pesquisas estatísticas. Que informações estão representadas nesse gráfico?

b) Em qual tipo de atividade há mais crianças e adolescentes trabalhando? Qual é a porcentagem?

c) Em sua opinião, por que a concentração de trabalho infantil é maior nessa atividade?

d) Quais atividades apresentam menor exploração do trabalho infantil? Qual é a porcentagem?

Fonte: ALVES, R.; BRUGNEROTTO, T. Vontade de saber Português $7^{\circ}$ ano. São Paulo: FTD, 2012, p.135. 
A seguir os autores apresentam um conjunto de atividades que visa comparar as informaçôes com outro texto lido, propiciando assim material para uso no seminário sugerido.

\section{QUADRO 2 - Atividade de produção oral}

\section{Em qual das atividades apresentadas nesse gráfico se enquadra o trabalho infantil denunciado na leitura 2 ?}

Agora você e seus colegas vão pesquisar mais sobre o trabalho infantil nas atividades destacadas no gráfico para posteriormente fazer uma exposição oral para a turma. Siga as orientaçôes.

O seminário deverá ser feito em grupos de três alunos.

Juntos, escolhem uma das atividades em que há a exploração do trabalho infantil, expostas no gráfico.

Depois pesquisem sobre os tipos de trabalho que podem se enquadrar na atividade escolhida.

Definam um tipo de trabalho infantil específico, de acordo com a atividade selecionada. Dividam a função de cada integrante do grupo, por exemplo, quem vai: conceituar o problema e listar as principais regióes em que ele ocorre;

mostrar as condiçôes de trabalho das pessoas nessa atividade; apresentar soluçóes para o problema.

Discutam as informaçóes que encontrarem para que todos possam saber o que o colega vai expor.

Fonte: ALVES, R.; BRUGNEROTTO, T. Vontade de saber Português 7o ano. São Paulo: FTD, 2012, p.135.

Após uma breve orientação relativa às funções que poderão ser assumidas durante a preparação e realização do seminário, são apresentados os passos que deverão ser seguidos pelos grupos de alunos. 
QUADRO 3 - Atividade de produção oral

\begin{tabular}{|c|c|c|}
\hline $\begin{array}{l}\text { Quando o relacionamento é } \\
\text { sério (75\%), o (a) parceiro } \\
\text { (a) é chamado (a) de: }\end{array}$ & $\begin{array}{l}\text { Quando náo } \\
\text { existe compromisso for- } \\
\text { mal (15\%), mas há envol- } \\
\text { vimento emocional, } \\
\text { chama-se o (a) } \\
\text { companheiro (a) de : }\end{array}$ & $\begin{array}{l}\text { Quando náo há nenhum } \\
\text { vínculo (10\%) emocio- } \\
\text { nal, os jovens resumem } \\
\text { assim seus relacio- } \\
\text { namentos: }\end{array}$ \\
\hline $\begin{array}{c}\text { namorado (a) } \\
\text { dos meninos) }\end{array}$ & ficante & tô pegando \\
\hline namorante & affaire & tô ficando \\
\hline caso sério & & tô beijando \\
\hline vip & & \\
\hline $\begin{array}{l}\text { radiopatrulha (no caso dos } \\
\text { ciumentos) }\end{array}$ & & \\
\hline
\end{tabular}

Fonte: ALVES, R.; BRUGNEROTTO, T. Vontade de saber Português 7o ano. São Paulo: FTD, 2012, p.136.

Observamos que as autoras conceituam o gênero elencando uma de suas principais características: exposição oral de informaçôes obtidas por meio de pesquisa. Entretanto, não há nenhuma abordagem quanto ao público-alvo ou à situação comunicativa. Compreendemos que, apesar de a atividade pressupor como situação comunicativa a interação entre alunos e professores no ambiente de sala de aula, seria importante que oferecesse alguma orientação sobre o público e a situação comunicativa. A utilização de um gráfico para contextualizar o tema é relevante, apesar de alguns questionamentos referentes a ele, que não discutiremos aqui por não fazer parte do objetivo de nossa análise.

Consideramos a proposta de produção do seminário pouco produtiva, já que as autoras não sistematizam adequadamente o gênero, embora destaquem informaçóes importantes para a realizaçáo da exposiçáo, como: organização dos dados pesquisados e elaboração de um roteiro de apresentação. Para Dolz e Schneuwly (2010), essa é uma parte essencial do trabalho de produçáo do texto que será apresentado, que garante a progressão temática. Há, também, 
a conscientização sobre o papel do aluno como expositor-especialista, pois a atividade sugere um momento de interação entre este e o auditório. Apesar disso, observamos que a atividade se baseia em propor um tema que sirva de mote para uma apresentação oral sem nenhuma preocupação com a apropriação da constituição de um gênero secundário. Não há nenhum tipo de informação quanto às características linguísticas do gênero ou às estratégias discursivas que garantirão a produção de um texto voltado para a construção de conhecimento.

\section{Atividade 2}

Essa atividade também faz parte da coleção Vontade de saber Português elaborada pelas autoras já citadas, mas agora destinada ao $8^{\circ}$ ano do ensino fundamental. A atividade é parte integrante do capítulo 2, que tem como temática a adolescência.

A atividade cita, no tópico Produção oral, os gêneros enquete e seminário. Cita as características da enquete, mas, ao propor a atividade oral, não menciona mais a palavra seminário, e sim apenas apresentação oral, o que reforça o tratamento inadequado do gênero em questão, pois náo considera sua dimensão comunicativa e sua finalidade. Também consideramos inadequadas as questóes discursivas sobre a enquete, e estas estáo reformuladas adiante. 


\section{QUADRO 4 - Atividade de produçáo oral}

\section{Produção oral}

\section{Enquete e seminário}

É comum, em algumas reportagens e notícias, a presença de gráficos ou infográficos, que representam dados coletados em pesquisas sobre assuntos específicos e de interesse público. Essas pesquisas são denominadas enquetes ou pesquisas de opiniáo.

A seguir, observe os dados obtidos a partir de uma pesquisa sobre relacionamento amoroso, feita com adolescentes de 13 a 19 anos.

\begin{tabular}{|c|c|c|}
\hline $\begin{array}{l}\text { Quando o relacionamento é } \\
\text { sério }(75 \%) \text {, o (a) parceiro (a) é } \\
\text { chamado (a) de: }\end{array}$ & \begin{tabular}{|l|} 
Quando náo existe compro- \\
misso formal (15\%), mas há en- \\
volvimento emocional, chama- \\
se o (a) companheiro (a) de : \\
\end{tabular} & $\begin{array}{l}\text { Quando nâo há nenhum vínculo } \\
(10 \%) \text { emocional, os jovens resu- } \\
\text { mem assim seus relacionamentos: }\end{array}$ \\
\hline namorado (a) & ficante & tô pegando \\
\hline $\begin{array}{l}\text { namorido (apenas no caso dos } \\
\text { meninos) }\end{array}$ & rolinho & tô ficando \\
\hline namorante & affaire & tô beijando \\
\hline \multicolumn{3}{|l|}{ caso sério } \\
\hline \multicolumn{3}{|l|}{ vip } \\
\hline $\begin{array}{c}\text { radiopatrulha (no caso dos } \\
\text { ciumentos) }\end{array}$ & & \\
\hline
\end{tabular}

1) Em sua opiniáo, por que muitas vezes as reportagens apresentam enquetes?

2) Quais dados estatísticos foram obtidos por meio da pesquisa de opinião?

3) Para você, a enquete contribuiria para formular argumentos para um artigo de opinião? Por quê?

4) Apesar de não apresentar porcentagem, é possível identificar o que foi mais votado em cada uma dessas pesquisas? Quais?

Agora você e seus colegas farão uma enquete com outros colegas da escola. O objetivo é fazer um levantamento das opinióes dos alunos sobre um determinado assunto. Após organizar as informaçōes, vocês deverão divulgá-las, por meio de uma apresentação oral, para seus colegas de sala.

- Primeiro, o professor deverá dividir a turma em grupos de três pessoas.

- Logo após, definam o assunto da enquete. Veja algumas sugestóes de enquetes.

a) Você acha que os adolescentes preferem ficar ou namorar?

b) Você acha que o fim do namoro pode prejudicar a amizade?

c) Em sua opinião, o excesso de ciúme prejudica o namoro?

d) Você se considera uma pessoa ciumenta?

Fonte: ALVES, R.; BRUGNEROTTO, T. Vontade de saber Português $8^{\circ}$ ano. São Paulo: FTD, 2012, p. 40. 
As autoras iniciam a proposta explorando as características da enquete ou pesquisa de opinião para posteriormente utilizar o seminário como meio para divulgação dos resultados de uma enquete. Novamente, não há sistematização do gênero seminário, que, neste caso, resume-se a uma simples apresentação oral apenas com o objetivo de expor os resultados da enquete feita pelos alunos.

A seguir, no quadro 5, são descritas as etapas para a concretização de uma atividade oral em sala de aula, também incluindo "dicas para que a atividade seja bem-sucedida".

\section{QUADRO 5 - Atividade de produção oral}

- Além dessas, é possível criar outras enquetes. Com os colegas, procurem pensar em questóes polêmicas cujas respostas possam ser "sim" ou "não". Se necessário, peçam ajuda ao professor.

- Escolhida a enquete, delimitem a quantidade de pessoas para aplicar a pesquisa.

- Definam a faixa etária ou o ano escolar do público para o qual a enquete será destinada.

- Com o professor, determinem um horário para realizar a pesquisa, que poderá ser feita durante o intervalo das aulas.

- Todos os integrantes do grupo deverão participar da enquete.

- Antes de realizar a atividade e abordar as pessoas, pergunte se elas se dispóem a participar da enquete.

- Anote todas as respostas em uma folha.

- Ao final da pesquisa, reúnam os dados levantados e montem um gráfico de setor cujos dados deverão ser apresentados oralmente à turma.

\section{Dicas para que a atividade seja bem-sucedida}

- Depois de realizarem a pesquisa e colocarem os dados em forma de gráfico de setor, planejem a apresentação oral dessas informaçóes.

- Para isso, vocês poderão utilizar diferentes recursos, como: lousas, transparências, slides e cartazes.

- Inicialmente, o grupo deverá justificar, na apresentação, a escolha do tema da enquete e especificar o público (faixa etária ou ano escolar) ao qual foi direcionada e quantas pessoas responderam à enquete.

(Continua) 
(Conclusão)

- A próxima etapa consiste na apresentação dos resultados do gráfico.

- Elaborem um roteiro, delimitando o que cada integrante do grupo vai falar, para que, durante a apresentaçáo, vocês possam dar sequência à fala do colega, evitando, dessa forma, o esquecimento ou a repetição de informaçóes.

- Façam um resumo em tópicos para entregar aos colegas. Assim, eles poderão fazer anotaçôes e ter o registro das informaçôes obtidas pela enquete.

- No momento da apresentaçáo, falem pausadamente e empreguem um tom de voz adequado para que todos possam compreender o que está sendo exposto.

- Ao final da apresentação, abram espaço para que os colegas tirem suas dúvidas sobre o assunto abordado e possam discutir os resultados da enquete.

Fonte: ALVES, R.; BRUGNEROTTO, T. Vontade de saber Português $8^{\circ}$ ano. São Paulo: FTD, 2012, p. 41.

As orientaçôes para a apresentação oral são expostas como dicas e não há determinação do propósito comunicativo. O caráter didático do gênero seminário é negligenciado se considerarmos que os temas escolhidos para a enquete não demandam nenhum tipo de aprendizagem. A inadequação da atividade suscitou a necessidade de reelaboração a partir dos pressupostos teóricos aqui apresentados. Apresentamos nossa sugestáo de reelaboração a seguir.

\section{Atividade reformulada}

Para a reformulação da atividade, sugerimos manter o diálogo com o gênero enquete. Entretanto, reelaboramos as questóes discursivas sobre a enquete apresentada a fim de explorá-la de forma mais produtiva. Apresentamos, a seguir, a enquete e as questôes discursivas que sugerimos acrescentar. 


\section{Atividade reformulada}

Para a reformulação da atividade, sugerimos manter o diálogo com o gênero enquete. Entretanto, reelaboramos as questóes discursivas sobre a enquete apresentada a fim de explorá-la de forma mais produtiva. Apresentamos, a seguir, a enquete e as questóes discursivas que sugerimos acrescentar.

\section{QUADRO 6 - Enquete}

\begin{tabular}{|c|c|c|}
\hline $\begin{array}{l}\text { Quando o relacionamento é sério } \\
\text { (75\%), o (a) parceiro (a) é chamado } \\
\text { (a) de: }\end{array}$ & $\begin{array}{l}\text { Quando náo existe compromisso } \\
\text { formal (15\%), mas há envolvi- } \\
\text { mento emocional, chama-se o(a) } \\
\text { companheiro(a) de : }\end{array}$ & $\begin{array}{l}\text { Quando náo há nenhum vínculo } \\
\mathbf{1 0} \text { (10) emocional, os jovens } \\
\text { resumem assim seus relacio- } \\
\text { namentos: }\end{array}$ \\
\hline $\begin{array}{c}\text { namorado (a) } \\
\text { namorido (apenas no caso dos } \\
\text { meninos) }\end{array}$ & rolinho & tô pegando \\
\hline namorante & affaire & tô beijando \\
\hline caso sério & & \\
\hline vip & & \\
\hline radiopatrulha (no caso dos \\
ciumentos)
\end{tabular}

Fonte: ANNA PAULA BUCHALLA. A juventude em rede. Veja. São Paulo: Abril, no 2100. 18 de fevereiro de 2009, p. 88.

A partir dos dados fornecidos pela enquete, sugerimos a seguinte reformulação da atividade:

\section{QUADRO 7 - Perguntas sugeridas sobre a enquete}

1. Observe a fonte de onde a enquete foi retirada. Há relação entre o título da reportagem e os dados apresentados? Justifique.

2. Quais dados estatísticos foram obtidos por meio da enquete?

3. Em sua opinião, uma enquete contribui para formular argumentos sobre o assunto apresentado? Por quê?

4. Qual o objetivo da inclusão de dados de pesquisa em um texto informativo?

Entre a análise da enquete e as orientações para a exposição oral, percebemos a necessidade de inserir um texto explicativo 
sobre o tipo e o gênero discursivos presentes na proposta de produção textual.

QUADRO 8 - Reelaboração da atividade: conceituação de texto expositivo

\section{Textos Expositivos}

Alguns textos que circulam na sociedade são produzidos com o objetivo de transmitir diferentes formas de saberes, contribuindo para a construçáo do conhecimento.

\section{Você sabia?}

O seminário é um dos gêneros textuais orais que tem como objetivo expor e debater informaçôes que possam gerar a construção de conhecimento por meio da interaçấo entre expositor e ouvinte. O seminário é constituido por duas etapas principais: o planejamento do texto e a exposição do texto.

Reformulamos, também, as orientações para a realização do seminário, pois, como já dissemos, a atividade trata o seminário como uma simples apresentação oral, apenas sintetizando as informaçôes básicas necessárias a qualquer apresentação oral, sem explorar os aspectos constitutivos desse gênero particular.

Organizamos as orientaçóes em três blocos: a pesquisa que norteará o trabalho; o momento de preparação da exposição com a organização interna do texto; e o momento da realização da exposição considerando os aspectos linguísticos e discursivos necessários à transmissão eficaz das informações. Esses três blocos são destacados nos quadros 9 a 11 . 
QUADRO 9 - Reelaboraçáo da atividade: orientaçóes quanto à pesquisa e coleta de dados

\section{Parte 1 - Pesquisa e coleta de dados}

Você e seus colegas organizaráo um seminário sobre um dos temas relacionados à adolescência:

- Adolescência e redes sociais;

- Gravidez na adolescência;

- O consumo de álcool na adolescência;

- A exploração do trabalho juvenil;

- O adolescente e os grupos sociais;

- Os distúrbios alimentares na adolescência.

Após escolher o tema, cada grupo deverá realizar uma enquete entre os alunos da escola, levantando questóes polêmicas sobre o assunto. Os resultados da enquete deverão ser apresentados durante o seminário. Esses dados serão ilustrativos, já que a apresentação será focada nas informaçôes pesquisadas sobre o assunto. Para isso, o grupo deverá pesquisar sobre o tema e, se julgar necessário, solicitar a ajuda dos professores de outras disciplinas. 
QUADRO 10 - Reelaboração da atividade: orientaçôes quanto ao planejamento do texto

\section{Parte 2 - Planejamento do texto}

Nessa etapa, realizaremos a preparação do texto que será apresentado. O expositor deverá fazer a seleção das informaçôes sobre o assunto que será abordado e organizá-las em informaçôes gerais e específicas. Em seguida, as informações deverão ser ordenadas em temas e subtemas a serem explorados de forma progressiva na exposição. $\mathrm{O}$ expositor deverá certificar-se de que essas informaçóes garantirão a coerência do texto, ou seja, que as informaçôes não sejam contraditórias entre si. Um recurso importante para essa fase é que o expositor organize o texto em tópicos como apoio para a oralizaçáo das informaçôes.

QUADRO 11 - Reelaboração da atividade: orientações quanto à apresentação do seminário

\section{Parte 3 - Apresentaçáo do seminário}

No momento da apresentação, o expositor deverá fazer a abertura do seminário saudando seus ouvintes e introduzindo o tema que será exposto. Em seguida, deverá indicar o plano da exposição, ou seja, os tópicos que serão abordados de acordo com a sequência da apresentação. Após esse momento, os tópicos serão desenvolvidos e as informaçôes deverão ser aprofundadas. É importante que o expositor sinalize, ao longo de sua fala, o plano esquemático de sua apresentação. Para isso, recorrerá às formas linguísticas disponíveis para sintetizar, exemplificar, reformular e articular as informaçóes a serem expostas. O expositor poderá, ao final de sua apresentação, lançar aos ouvintes um questionamento que servirá como base para a discussão sobre o assunto. Esse é um momento importante para promover a troca de conhecimento entre o público e o expositor.

Durante a apresentaçáo, os grupos poderão utilizar diferentes recursos, como lousa, cartazes e slides. $\mathrm{O}$ uso desses recursos pode tornar a exposiçáo mais interativa, além de facilitar a compreensão do assunto exposto. 


\section{Atividade 3}

Essa atividade faz parte da coleção Português linguagens, elaborada por William Roberto Cereja e Thereza Cochar Magalhães, editada pela Saraiva e destinada ao $8^{\circ}$ ano do ensino fundamental. A atividade é parte integrante do capítulo 3, o qual não apresenta uma temática específica.

Os autores abrem a seção conceituando o gênero seminário. Abordam o propósito comunicativo e as esferas sociais em que o gênero pode ocorrer. Em relação às atividades anteriores, este é um aspecto positivo desta atividade, pois demonstra que o gênero será tratado a partir de suas especificidades, contribuindo para a aprendizagem dos alunos.

\section{QUADRO 12 - Trecho de atividade}

\section{O SEMINÁRIO}

O seminário é um gênero oral público que pertence à família dos gêneros expositivos, como o texto de divulgação científica, o relatório, o verbete de enciclopédia, o texto didático. Comum na esfera escolar, acadêmica e profissional, o seminário pode ser realizado individualmente ou em grupo. Seu papel é transmitir conhecimentos específicos - técnicos ou científicos - a respeito de um assunto relacionado a determinada área do conhecimento.

Neste capítulo e no seguinte, você vai aprender a realizar um seminário.

Fonte: CEREJA, W. R.; MAGALHÃES, T. C. Português linguagens $8^{\circ}$ ano. 7. ed. São Paulo: Saraiva, 2012, p. 236.

Os autores sistematizam a abordagem do gênero em uma seçáo mais extensa do que a das atividades anteriormente citadas, tratando de cada parte constitutiva do seminário. Vejamos detalhadamente a seção: 


\section{QUADRO 13 - Trecho de atividade}

\section{Planejamento e preparaçáo de um seminário}

Já que o seminário é um gênero que tem por objetivo a transmissão de conhecimentos, é fundamental que o apresentador esteja muito bem preparado em relação ao assunto a ser abordado. Por isso, é necessário planejar e preparar o seminário, passando por várias etapas, descritas a seguir.

\section{Pesquisa}

Pesquise em livrarias e bibliotecas, na Internet e em locadoras quais livros, enciclopédias, jornais, revistas especializadas, vídeos, etc, poderão servir como fontes de informação sobre o tema.

\section{Tomada de notas}

Tome notas, resuma ou reproduza textos verbais que possam ser úteis para a exposição. Esse trabalho deve ter em vista a produção de um roteiro para ser utilizado no momento da apresentação. Por isso, anote tudo o que for útil para enriquecer o seu texto: dados históricos ou estatísticos, citaçóes, comparaçóes, exemplos, etc.

\section{Seleçáo e organizaçáo de informaçóes e recursos materiais}

Selecione e organize as informaçóes, tendo em vista os seguintes aspectos da exposição:

· Como introduzir, desenvolver e concluir a exposição;

· Quais subtemas serão abordados no desenvolvimento;

- Quais exemplos ou apoios (gráficos, dados estatísticos) serão utilizados para fundamentar a exposição;

- Que materiais e recursos audiovisuais (cartazes, apostilas, lousa, retroprojetor, datashow, microfone, etc) serão necessários.

Nesse planejamento, devem ser levadas em conta as características do públicoalvo, como faixa etária, tipos de interesse, expectativas e conhecimentos prévios em relação ao tema abordado. Para dar à exposição um encaminhamento agradável, é importante intercalar o uso da voz com o uso de recursos audiovisuais.

Fonte: CEREJA, W. R.; MAGALHÂES, T. C. Português linguagens $8^{\circ}$ ano. 7. ed. São Paulo: Saraiva, 2012, p. 237.

Observamos que os autores explicitam novamente o propósito comunicativo do seminário e elencam a importância da pesquisa e organização dos dados obtidos. No subitem Seleção e organização de informaçóes e recursos materiais, os autores sintetizam as fases de 
organização das informaçóes e propóem etapas importantes para a organização interna do texto. Também destacam a importância de considerar o público-alvo a fim de promover a adequação da exposição. Vejamos outra etapa da proposta.

QUADRO 14 - Trecho de atividade

\section{Produção de roteiro e esquema}

Primeiramente, redija um roteiro que permita visualizar não apenas o conjunto das informaçôes que serão apresentadas, mas também a sequência em que isso vai ocorrer. Esse roteiro deve conter: informaçôes- chave que orientarão seu pensamento durante a exposição; indicação de recursos audiovisuais; textos de autoridades ou especialistas que serão citados, etc. Durante a exposição propriamente dita, deve-se evitar ler o que está escrito no roteiro, a não ser para reproduzir textualmente a citaçáo de outro autor. Posteriormente, redija um esquema, isto é, um conjunto de anotaçóes breves que lhe serviráo como apoio durante a exposição. Se necessário, você poderá olhar rapidamente o esquema, a fim de se lembrar de algum tópico ou da sequência da exposição.

\section{Ensaio}

Ensaie sua apresentação. Para isso, tenha à mão um gravador e o esquema. Com o gravador ligado, comece a exposiçáo como se estivesse falando para a classe. Procure falar com segurança e fluência, evitando consultar o roteiro. Faça-o apenas em último caso. Quando terminar, ouça a gravaçáo e avalie o resultado. Se julgar necessário, ensaie outras vezes e, se possível, na presença de outras pessoas.

Fonte: CEREJA, W. R.; MAGALHÃES, T. C. Português linguagens $8^{\circ}$ ano. 7. ed. São Paulo: Saraiva, 2012, p. 238.

Novamente, observamos as etapas que antecedem a exposição, o que reforça a ideia do seminário como gênero secundário. Essa abordagem reitera as palavras de Goulart (2005, p. 137), para quem o seminário "é um gênero mais complexo e elaborado e, por essa razão, necessita de sistematização para que dele nos apropriemos". Lamentamos, porém, que os autores não tenham abordado as estratégias discursivas nesta fase. Acreditamos que no subitem Ensaio deveria haver espaço para tratar esse aspecto táo relevante para o desenvolvimento adequado da exposiçáo. 
No item Sequência e andamento da exposição (apresentado a seguir), percebemos a teorizaçáo de Dolz e Schneuwly (2010) permeando a organizaçáo das etapas da apresentaçáa. Em seus estudos sobre a exposiçáo oral, os teóricos relacionam as fases da apresentaçáo oral: abertura, introdução do tema, apresentaçấo do plano de exposiçáo, desenvolvimento e encadeamento de diferentes temas, recapitulação e síntese, conclusão e encerramento. Podemos observar que os autores da coleçáo também definem essas fases, conferindo à atividade um suporte mais adequado às estratégias de ensino voltadas para o domínio dos gêneros.

QUADRO 15 - Trecho de atividade

\section{Sequência e andamento da exposiçáo}

1. Abertura: o professor (ou um colega) dá a palavra ao apresentador. Faz isso com palavras como "Vocês agora vão assistir ao seminário preparado por fulano..."

2. Tomada da palavra e cumprimentos: o apresentador coloca-se à frente da plateia, cumprimenta-a e dá início ao seminário.

3. Apresentação do tema: o apresentador diz qual é o tema, fala da importância de abordá-lo e esclarece o ponto de vista a partir do qual irá abordá-lo. Se o tema for amplo, delimita-o, isto é, indica qual aspecto dele será enfocado. Por exemplo, se o tema é a poluição do meio ambiente, o apresentador pode delimitá-lo e tratar apenas da poluição dos rios. Esse momento do seminário tem em vista despertar na plateia curiosidade sobre o tema abordado.

4. Exposição: o apresentador segue o roteiro traçado, expondo cada uma das partes, com clareza e sem atropelos. Ao final de cada uma, deve perguntar ao público se alguém quer fazer alguma pergunta.

5. Conclusão e encerramento: o apresentador retoma os principais pontos abordados, fazendo uma síntese deles; se quiser, pode mencionar aspectos do tema que merecem ser aprofundados em outros seminários; pode também deixar uma mensagem final, algo que traduza o seu pensamento ou o pensamento do grupo ou de um autor especial. No final, agradece a atenção do público e passa a palavra a outra pessoa.

6. Tempo: $\mathrm{O}$ apresentador deve estar atento ao tempo previsto e, de acordo com o andamento do seminário, ser capaz de introduzir ou eliminar exemplos e aspectos secundários, caso haja necessidade.

Fonte: CEREJA, W. R.; MAGALHÃES, T. C. Português linguagens $8^{\circ}$ ano. 7. ed. São Paulo: Saraiva, 2012, p. 239. 
Ao lado da sequência proposta, os autores apresentam um material que destaca o valor dos recursos tecnológicos no apoio aos apresentadores.

QUADRO 16 - Trecho de atividade

Enriquecendo o seminário com o uso de recursos audiovisuais
A principal linguagem de um seminário é a verbal. Contudo, o uso de recursos
audiovisuais, como cartazes, transparências em retroprojetor, filmes, slides, DVD,
datashow, etc, pode tornar o evento mais agradável ou facilitar a transmissão de um
volume maior de informaçóes. O uso desses recursos exige, porém, certos cuidados:
O equipamento deve ser testado previamente, para prevenir a ocorrência de
falhas técnicas durante a exposição.
O apresentador deve lembrar que tais recursos têm a finalidade de servir de
apoio à exposição oral e, portanto, não a substituem. Ao fazer uso de uma
transparência, por exemplo, ele deve aproveitá-la para reunir ou esquematizar
as informaçóes que vem apresentando, em vez de simplesmente ler o que está
escrito nela.
A alternância da exposição oral com o uso de recursos audiovisuais geralmente dá
leveza a um seminário.

Fonte: CEREJA, W. R.; MAGALHÃES, T. C. Português linguagens $8^{\circ}$ ano. 7. ed. São Paulo: Saraiva, 2012, p. 239.

$\mathrm{Na}$ etapa seguinte, merece atenção o subitem Uso da linguagem, no qual os autores elencam algumas características linguísticas relevantes para a exposição. Novamente, lamentamos que essas características tenham sido pouco exploradas no material, pois haveria espaço para outros aspectos importantes, como a reformulação e a marcação temporal da fala por meio dos tempos verbais. 
QUADRO 17 - Trecho de atividade

\section{Uso da linguagem}

Nos seminários, predomina a norma - padrão da língua, embora possa haver menor ou maior grau de formalismo, dependendo da intimidade entre os interlocutores. Assim:

1. O apresentador deve evitar certos hábitos da linguagem oral, como a repetição constante de expressôes com tipo, tipo assim, né, tá, ahnn...pois elas prejudicam a fluência da exposição.

2. Sempre que for necessário, o apresentador deve explicar o significado de vocábulos e conceitos específicos da área pesquisada; para isso, deve fazer uso de expressóes de reformulaçáo, como isto é, quer dizer, como, por exemplo, em outras palavras, vocês sabem o que é isso? Deve também fazer uso de expressóes que confirmam continuidade ao texto, como além disso, por outro lado, outro aspecto, apesar disso.

Fonte: CEREJA, W. R.; MAGALHĀES, T. C. Português linguagens $8^{\circ}$ ano. 7. ed. São Paulo: Saraiva, 2012, p. 240.

Os autores ainda ressaltam a importância de articulação entre os enunciados de diferentes expositores para garantir a coesão textual. Os temas para o seminário só serão expostos na seção denominada Intervalo, que se encontra no final do capítulo e, portanto, não serão expostos aqui. Mas ressaltamos que os temas se referem à conscientização ambiental, sendo considerados relevantes do ponto de vista pedagógico e atendendo ao caráter de técnica de ensino socializado do gênero seminário. 


\section{Consideraçóes finais}

Neste estudo, foi possível constatar que as práticas de oralidade na escola ainda estão distantes de promover o real desenvolvimento dessa modalidade da língua em nossos educandos. Ao analisarmos alguns manuais didáticos, observamos que, em linhas gerais, não há um objetivo claro em relaçấo ao trabalho com os gêneros orais e que este constitui, muitas vezes, a simples oralizaçáo de um texto escrito. No debate didático, há um consenso de que a maioria dos alunos náo sabe fazer uso da linguagem oral de maneira adequada e que caberia à escola trabalhar para promover o bom desempenho dos alunos ao falar em público. O posicionamento é pertinente, entretanto acreditamos que, se não houver um trabalho sistemático e organizado quanto às instâncias linguísticas e discursivas constituintes dos gêneros orais, não haverá avanço em relação ao desenvolvimento da competência discursiva oral na educação básica. A sistematização no ensino dos gêneros orais é apontada pelos teóricos como o caminho para um ensino mais eficaz de língua materna: "Quanto mais precisas as dimensōes ensináveis de um gênero, mais elas facilitarão a apreensão deste como instrumento e possibilitará o desenvolvimento de capacidades de linguagem diversas que a ele estáo associadas" (SCHNEUWLY; DOLZ, 2010, p. 76).

Assim, acreditamos que a escola deva tornar relevante o trabalho com os gêneros orais tanto quanto o trabalho com os gêneros escritos, a fim de que o ensino de língua portuguesa possa ser mais produtivo e significativo para nossos alunos, contribuindo, de fato, para o seu desenvolvimento social. 


\section{REFERÊNCIAS}

BAKHTIN, Mikhail. Os gêneros do discurso. In: Estética da criação verbal. São Paulo: Martins Fontes, 1992. p. 277-326.

BERNARDES, Adair Vieira; GONÇALVES, Elizete de Souza. O gênero seminário: usos e dimensões ensináveis. Revista Linguasagem, São Carlos, 2010. Disponível em: <http://www.letras.ufscar.br/> Acesso em 15. dez. 2013.

BRASIL. Ministério da Educação. Secretária de Educação Básica. Parâmetros curriculares nacionais de língua portuguesa. Brasília: MEC, 1997. Disponível em: <http://portal.mec.gov.br/seb/arquivos/pdf/livro02.pdf>. Acesso em 07. dez. 2014.

DOLZ, Joaquim; SCHNEUWLY, Bernard; HALLER, Sylvie. O oral como texto: como construir um objeto de ensino. In: SCHNEUWLY, B.; DOLZ, J. (Org.). Gêneros orais e escritos na escola. Tradução Roxane Rojo; Glaís Sales Cordeiro. 2. ed. São Paulo: Mercado de Letras, 2010. p. 125-155.

DOLZ, Joaquim et al. A exposição oral. In: SCHNEUWLY, B.; DOLZ, J. Gêneros orais e escritos na escola. Tradução Roxane Rojo; Glaís Sales Cordeiro. 2. ed. São Paulo: Mercado de Letras, 2010. p. 183-211.

GOULART, Cecília. As práticas orais na escola: o seminário como objeto de ensino. Campinas, 2005. 210p. Dissertação (Mestrado em Linguística Aplicada) - Instituto de Estudos da Linguagem, Universidade Estadual de Campinas.

SCHNEUWLY, Bernard; DOLZ, Joaquim. Gêneros orais e escritos na escola. Tradução Roxane Rojo; Glaís Sales Cordeiro. 2. ed. São Paulo: Mercado de Letras, 2010.

SCHNEUWLY, Bernard; DOLZ, Joaquim. Os gêneros escolares - das práticas de linguagem aos objetos de ensino. In: SCHNEUWLY, B.; DOLZ, J. (Org.). Gêneros orais e escritos na escola. Tradução Roxane Rojo; Glaís Sales Cordeiro. 2. ed. São Paulo: Mercado de Letras, 2010. p. 61-78. 